\title{
Las actividades organizadas para los turistas como elemento de cohesión en los destinos residenciales de montaña: el caso de la Cerdanya
}

\author{
José M. a Prat Forga \\ Universidad Nacional de Educación a Distancia (UNED) \\ Grupo de investigación TUDISTAR (UAB) \\ jmpratf@gmail.com
}

\section{Gemma Cànoves Valiente}

Universitat Autònoma de Barcelona

Grupo de investigación TUDISTAR (UAB)

gemma.canoves@uab.cat

\section{Resumen}

La mayor facilidad de movilización de la población urbana ha provocado un importante aumento de las viviendas secundarias en los territorios de interior. En algunos de estos destinos turísticos dicho crecimiento ha ido parejo a la intensificación de las actividades deportivas, culturales, recreativas y de ocio ofertadas desde los organismos públicos y las asociaciones locales, con el objetivo de satisfacer las demandas de esta población temporal, alargar su estancia en el destino y relacionarla con la población permanente, a fin de evitar los conflictos sociales entre estos colectivos.

En el presente trabajo, a partir de datos estadísticos, de las programaciones de actividades publicadas en la prensa gratuita local y de una encuesta realizada a 154 personas, se analiza el caso de la parte española de la comarca de la Cerdanya, con el objetivo de comprobar si hay una relación directa entre estas actividades, las segundas residencias y la población estacional, así como el grado de satisfacción obtenido con dichas actividades.

Palabras clave: segundas residencias; actividades turísticas; satisfacción; nuevos espacios sociales; Pirineos; Cataluña 
Resum. Les activitats organitzades per als turistes com a element de cohesió de les destinacions residencials de muntanya: el cas de la Cerdanya

La facilitat de mobilització més gran per part de la població urbana ha provocat un important augment dels habitatges secundaris als territoris d'interior. En algunes d'aquestes destinacions turístiques el creixement ha tingut lloc juntament amb l'augment de les activitats esportives, culturals, recreatives i d'oci ofertes des dels organismes públics i les associacions locals, amb l'objectiu de satisfer les demandes d'aquesta població temporal, allargar-ne l'estada en la destinació i relacionar-la amb la població permanent, a fi d'evitar els conflictes socials entre aquests collectius.

En el present treball, a partir de dades estadístiques, de les programacions d'activitats publicades a la premsa gratuïta local i d'una enquesta realitzada a 154 persones, s'hi analitza el cas de la part espanyola de la comarca de la Cerdanya, amb l'objectiu de comprovar si hi ha una relació directa entre aquestes activitats, les segones residències i la població estacional, com també quin és el grau de satisfacció obtingut amb aquestes activitats.

Paraules clau: segones residències; activitats turístiques; satisfacció; nous espais socials; Pirineus; Catalunya

Résumé. Les activités organisées pour les touristes en tant qu'élément de cohésion dans les destinations résidentielles de montagne: Le cas de la Cerdagne

La plus grande facilité de mobilisation de la population urbaine a provoqué une croissance importante des résidences secondaires dans les territoires d'intérieur. Dans certaines de ces destinations touristiques cette croissance s'est effectuée parallèlement à l'augmentation des activités sportives, culturelles, récréatives et d'oisiveté, proposées par les organismes publics et les associations locales dans l'objectif de satisfaire les demandes de cette population temporelle, d'allonger la durée des séjours dans la destination et d'établir des relations avec la population permanente, en évitant les conflits sociaux entre ces collectifs.

Dans ce travail, à partir des données statistiques, des programmations d'activités publiées dans la presse gratuite locale et d'une enquête réalisée auprès de 154 personnes, nous analysons le cas de la partie espagnole de la contrée de la Cerdagne, dans l'objectif de vérifier s'il y a une relation directe entre ces activités, les résidences secondaires et la population saisonnière, et quel est le degré de satisfaction obtenu au travers de ces activités.

Mots-clés: résidences secondaires; activités touristiques; satisfaction; nouveaux espaces sociaux; Pyrénées; Catalogne

Abstract. Activities organized for tourists as an element of cohesion in mountain residential destinations: The case of the Cerdanya

The greater ease of mobilization of the urban population has led to a significant increase in second residences. This growth has occurred on a par with an increase in sports, cultural, recreational and leisure activities offered by public bodies and local associations to satisfy the demands of this temporary population, who lengthen their stay at the destination and relate to the permanent population, thus avoiding social conflicts between these groups. This paper examines the case of the Spanish part of the region of the Cerdanya using statistical data on the programming of activities published in the free local press and a survey of 154 people. The aim is to verify if there is a direct relationship between these activities, second residences and the seasonal population, as well as the degree of satisfaction with these activities.

Keywords: second residences; tourist activities; satisfaction; new social spaces; Pyrenees; Catalonia 


\section{Sumario}

1. Introducción, objetivos e hipótesis 2. Metodología aplicada

3. Los nuevos espacios de ocio y recreación en el mundo rural
4. Análisis del caso

5. Conclusiones

Referencias bibliográficas

\section{Introducción, objetivos e hipótesis}

En las últimas décadas, en las sociedades desarrolladas se ha producido un cambio fundamental de actitud en la población urbana que puede asociarse a la postmodernidad (Soja, 1989; Harvey, 1994; Zukin, 1995). Mucha gente que vive en las ciudades desea mantener un cierto contacto con la naturaleza y con el medio rural disfrutando de sus paisajes, conociendo su sociedad, su cultura y sus formas de vida, su historia y su patrimonio, de un modo a veces no exento de una cierta nostalgia del pasado (Pallarès y Riera, 1991; Hall y Williams, 2002; Urry, 2002; Prat y Cànoves, 2012; Vargas del Río, 2015).

Con las mejoras en las infraestructuras del transporte, el aumento del nivel de vida y el mayor tiempo libre disponible, aparecen nuevas necesidades de ocio de la población urbana que se satisfacen mediante desplazamientos temporales (vacaciones de verano, Semana Santa, Navidad, Fin de Año, fines de semana, puentes de festivos) a lugares más o menos alejados de su residencia habitual, con el objetivo de consumir los bienes y los recursos allí presentes. Entre estos destinos destacan aquellos que se encuentran suficientemente cercanos desde el punto de vista temporal (a menos de dos horas de viaje), de manera que, cuando estos desplazamientos se transforman en habituales, se suelen convertir en residencias secundarias (Antón e Ibarguren, 1993; Fraguell, 1994; López Colás y Módenes, 2005; Cuadrado et al., 2017).

De esta forma, en estos destinos fácilmente accesibles, con un paisaje atractivo y significativos recursos naturales y/o culturales, se crean nuevos espacios de ocio. Este fenómeno está muy influenciado por los factores económicos y sociales de las personas, entre los que se pueden destacar, especialmente, el posicionamiento social (a mayor poder adquisitivo se tiende a disponer de más residencias secundarias y rodearse de vecinos de características similares) y los intereses económicos (invertir el capital en bienes inmuebles con ánimo de obtener futuras plusvalías) (Antón e Ibarguren, 1993; Indovina, 2003; Müller et al., 2004; Mazón y Aledo, 2005; Delgado, 2008; García González et al., 2008).

Estos desplazamientos temporales de la población urbana hacia el mundo rural provocan movimientos periódicos de expansión y compresión de la ciudad, no solo como forma de huir de la metrópoli, sino que, teniendo en cuenta que en el actual mundo globalizado los fenómenos urbanos son metropolitanos, el propio espacio urbano se expande temporalmente (Antón e Ibarguren, 1993; Indovina, 2003). 
En dicho contexto, estos destinos relativamente cercanos a las grandes aglomeraciones humanas ponen en valor turístico su patrimonio natural y/o cultural y ven aumentar la cantidad de residencias secundarias allí presentes. No obstante, este auge no evita la alta temporalidad de la población flotante. Por ello, desde los organismos públicos y las asociaciones locales, se organizan y se promocionan, a lo largo de todo el año, una serie de actividades de ocio y recreación, culturales y deportivas, que muchas veces son gratuitas y que, además de satisfacer las demandas de la población allí presente - tanto si se trata de la permanente como de la temporal-, ayudan a retener a este último colectivo más tiempo en el destino, ya que de ello se deriva un mayor consumo de bienes y servicios locales y una mayor riqueza económica para el territorio (creación de puestos de trabajo, aumento de ingresos, etc.).

Ante esta situación, el objetivo del presente estudio es analizar cómo en un destino relativamente cercano a las grandes aglomeraciones urbanas, donde el turismo y las segundas residencias se han convertido en su principal motor económico, desde los organismos públicos (ayuntamientos, consejos comarcales, etc.) y desde las asociaciones locales, se están programando, cada vez con mayor intensidad, múltiples actividades que satisfagan las nuevas demandas de ocio y recreación de una población urbana cada vez más experimentada, con nuevas motivaciones, mayores exigencias de calidad en los productos y en los servicios a consumir y que reclama un tratamiento personalizado (Prat y Cànoves, 2012).

Para ello se analiza el caso de la comarca de la Cerdanya, en los Pirineos catalanes, concretamente la parte española (que a partir de ahora denominaremos Baixa Cerdanya para distinguirla de la francesa o Alta Cerdanya), y ver qué actividades culturales y recreativas programan estos organismos a lo largo del año en cada uno de los municipios de la comarca. En el estudio analizaremos tres cuestiones:

- Primera, cuál ha sido la evolución del fenómeno del desarrollo turístico y de las segundas residencias en estos últimos años y cuáles son y cómo han evolucionado las actividades programadas por los organismos públicos y las asociaciones.

- Segunda, si existe alguna relación entre las viviendas secundarias, la población turística y dichas actividades.

- Tercera, cuál es el grado de satisfacción de la población, permanente y turística, con estas actividades y si se vislumbran conflictos en referencia al uso del espacio público.

En concreto, las hipótesis que se plantean son las siguientes:

1. Estas actividades han aumentado en los últimos años, provocan un alto grado de satisfacción a sus espectadores y participantes y no generan conflictos en el uso del espacio público. 
2. Hay una fuerte relación entre las residencias secundarias y dichas actividades, que va aumentando a medida que crecen ambas.

Así, después de la presente introducción, señalando los objetivos y las hipótesis a contrastar, se detalla la metodología utilizada y se expone sintéticamente el marco teórico existente sobre los nuevos espacios de ocio y recreación en el mundo rural y sobre la diversificación de la oferta de actividades para los turistas que, en estos destinos consolidados, programan, subvencionan o promocionan las administraciones públicas y las asociaciones locales. Después, se analiza el caso concreto de la Baixa Cerdanya, presentando los principales datos demográficos, de las viviendas y de los establecimientos turísticos de la comarca (hoteles y hostales, casas de turismo rural, cámpines), así como los resultados de una encuesta realizada sobre dichas actividades, analizando las posibles correlaciones lineales existentes entre variables y comprobando las hipótesis planteadas. A continuación, se exponen las conclusiones, así como posibles factores de discusión y líneas futuras de investigación. Finalmente, se relaciona la bibliografía consultada.

\section{Metodología aplicada}

Para comprobar las hipótesis aquí planteadas, primero se ha consultado parte de la profusa bibliografía académica existente sobre el desarrollo de las segundas residencias y la ciudad difusa (entre otros, Harvey, 1994; Nel.lo, 1996; Gustafson, 2002; Hall y Williams, 2002; Urry, 2002; Indovina, 2003; Serrano, 2003; Torres, 2003, Müller et al., 2004; Vivas, 2004; Módenes y López Colás, 2005; Delgado, 2008; García González et al., 2008; Scott, 2008; De Souza, 2012; Vargas del Río, 2015; Cuadrado et al., 2017).

Después se han recogido los principales datos estadísticos de los diferentes tipos de establecimientos turísticos existentes en la comarca en 2015 (cantidad y plazas disponibles), así como sobre las viviendas, publicados por el Institut d'Estadística de Catalunya (IDESCAT), algunos de ellos a partir de los censos de población y vivienda del Instituto Nacional de Estadística (INE) de los años 1981, 1991, 2001 y 2011, así como los censos de población residente y de población estacional desde el 2002 hasta el 2016.

$\mathrm{Al}$ respecto, hay que tener en cuenta que la población estacional indica la carga de habitantes que soporta anualmente cada municipio de la comarca, incluyendo todas aquellas personas que tienen alguna vinculación con ella, sean residentes o que acuden allí temporalmente por motivos de trabajo, estudios o vacaciones, tanto en residencias propias como en casas de amigos o en establecimientos turísticos. Asimismo, la población ETCA (población equivalente a tiempo completo anual) es la que se encuentra presente en el municipio. Para ello se suman a la población residente (población empadronada) las entradas de población no residente y se restan las salidas de población residente. Por su parte, la población estacional ETCA (equivalente a tiempo completo anual) es el saldo de las entradas de la población no residente en el 
municipio y las salidas de la residente en el municipio (es decir, la población estacional ETCA no residente es la población ETCA menos la población residente) (IDESCAT, 2017).

A su vez, el cálculo estimativo de viviendas secundarias (RS) en 2006 y 2016 se ha obtenido extrapolando los datos oficiales de los censos de 2001 y 2011 y aplicando las dos fórmulas siguientes:

$$
\begin{aligned}
& \mathrm{RS}_{2006}=\left(\mathrm{RS}_{2001}+\mathrm{RS}_{2011}\right) / 2 \\
& \mathrm{RS}_{2016}=\mathrm{RS}_{2011}+\left(\mathrm{RS}_{2011}-\mathrm{RS}_{2001}\right) / 2
\end{aligned}
$$

A continuación, se han revisado, seleccionado y unificado todas las actividades culturales y recreativas, organizadas y/o promocionadas desde los organismos públicos y las asociaciones locales, que se realizaron en cada uno de los municipios de la Baixa Cerdanya a lo largo de los años 2006 y 2016 y que se publicaron mensualmente en la prensa gratuita local (en concreto, en las revistas Pànxing Tot Cerdanya, Reclam y Viure als Pirineus).

Hay que tener en cuenta que este tipo de comunicación local, que ha experimentado una importante alza en Cataluña, desde 1975 en papel y desde 2010 también en formato digital, ofrece a sus lectores no solamente noticias y publicidad de proximidad, sino que además incluye las actividades de este tipo que se realizan en sus municipios (Costa y Puntí, 2013).

Para ello, primero se revisaron todas las actividades programadas en dichas revistas en estos dos años por los organismos públicos de la comarca (ayuntamientos y consejo comarcal) y por las asociaciones locales sin ánimo de lucro. Después, se seleccionaron todas las actividades que estaban relacionadas con la naturaleza, la cultura o que tenían un aspecto lúdico (bailes, comidas, meriendas, etc.). De ello se obtuvo la lista que se presenta en la figura 5.

Seguidamente, con el objetivo de confirmar las hipótesis aquí propuestas, se analizaron las posibles correlaciones lineales entre las segundas residencias (según los censos de 2001 y 2011 y las estimaciones de 2006 y 2016) y las actividades ofertadas en los municipios de la comarca en los años 2006 y 2016. Para ello se han calculado los coeficientes de Pearson (R) y de determinación $\left(\mathrm{R}^{2}\right)$, los cuales dan, respectivamente, información sobre la significancia de la correlación (el grado de influencia de una variable en la otra) y sobre la medida en que una variable explica la otra.

Finalmente, con el fin de comprobar el grado de involucración y satisfacción con estas actividades de la población que acude a dichos eventos, sea con residencia permanente, con segunda vivienda o pernoctando en los establecimientos turísticos de la comarca, se realizó, a lo largo del año 2016, una encuesta personal, al azar y sin distinción de género ni edad, a 154 personas que acudían a presenciar y/o a participar en algunas de las actividades programadas.

Dicha encuesta, que fue llevada a cabo personalmente por el autor de este artículo y otros colaboradores del Grup de Recerca Cerdanya (GRC), intentaba averiguar el grado de satisfacción con la actividad, el grado de participación 
directa en ella, la posibilidad de repetirla y de prescribirla a otras personas. Para ello se debía dar una valoración cuantitativa del modo siguiente: 1 (muy bajo), 2 (bajo), 3 (medio), 4 (alto) y 5 (muy alto). Además, se preguntaba a los encuestados si vivían permanentemente en la comarca, si residían en una vivienda secundaria o si estaban en un establecimiento turístico. En el caso de que no pudiesen incluirse en ninguna de estas tipologías, no se les consideraba. El resultado de los 154 encuestados fue que 35 (el 22,73\%) vivían permanentemente en alguna población de la Baixa Cerdanya; 94 (el 61,04\%) lo hacían temporalmente en una residencia secundaria de la comarca, en régimen de compra o de alquiler, y los restantes 25 (el 16,23\%) se encontraban alojados en un establecimiento turístico.

\section{Los nuevos espacios de ocio y recreación en el mundo rural}

A finales del siglo XIX, con el derrocamiento de las murallas de las grandes ciudades europeas, la alta burguesía empezó a construir sus mansiones principales, más espaciosas, suntuosas y con más comodidades, en las afueras del antiguo casco urbano; además de comprar solares más o menos situados en la misma zona, dentro de un plan de futura especulación inmobiliaria (Gili, 2003; Mazón y Aledo, 2005).

Poco a poco también empezó a construir residencias secundarias un poco más lejos, en el campo, para disfrute familiar de la naturaleza y el mundo rural, especialmente en verano (Pallarès y Riera, 1991; Nel.lo, 1996). De esta forma, algunos de estos territorios más alejados del núcleo metropolitano se fueron convirtiendo en destinos turísticos asociados al veraneo, la salud y el montañismo, y, en el caso de disponer de abundante nieve en invierno, también fueron pioneros en la práctica del esquí. Poco a poco, por mimetismo social, el resto de la clase burguesa urbana también accedió más modestamente a este tipo de viviendas. No obstante, las deficientes comunicaciones (malas carreteras, parque automovilístico muy limitado) y la poca disponibilidad de tiempo libre (semanas laborales de seis días) limitaron el crecimiento turístico de estos destinos más alejados de la metrópoli (Indovina, 2003).

En la actualidad, gracias al poder adquisitivo más elevado de la población, la mayor disponibilidad de tiempo libre para el ocio y la recreación, el desarrollo del turismo, el consumismo, el deseo de recuperar el contacto con la naturaleza, el interés en escaparse de las aglomeraciones y el estrés de las ciudades, la mayor concienciación sobre la salud personal y sobre el medio ambiente, la generalización del uso del automóvil y las nuevas motivaciones de la población urbana, junto con las sustanciales mejoras establecidas en los transportes y sus infraestructuras, lo cual reduce significativamente las distancias temporales entre algunos de estos destinos y las áreas urbanas e incrementa la movilidad entre ambos territorios, se han creado verdaderos espacios de flujo (Serrano, 2003; Torres, 2003; Vivas, 2004; Módenes y López, 2005; Delgado, 2008; Zárate y Rubio, 2011; Miralles y Tulla, 2012; Prat y Cànoves, 2012; Prat y Díaz, 2014). 
Este fenómeno ha permitido que, siguiendo el modelo de Lundgren (1974) sobre el aumento de la superficie urbana y las viviendas secundarias, que hace depender la expansión de las segundas residencias del crecimiento de las ciudades y de la urbanización de la sociedad, con áreas estables de segunda residencia y áreas más alejadas pero potencialmente recreativas (con el tiempo y con la conversión de la ciudad en área metropolitana, se van transformando sucesivamente en áreas de segunda residencia en transición; áreas de segunda residencia absorbidas por la ciudad, y nuevas áreas de segunda residencia), se amplíe el radio de localización de las viviendas secundarias y se incremente su frecuencia de uso (Zárate y Rubio, 2011).

Esta creciente movilidad de la población urbana ha provocado que algunos pueblos más alejados de las ciudades, y casi sin habitantes permanentes, hayan sido colonizados por las segundas o terceras residencias, las cuales, sin embargo, permanecen vacías durante gran parte del año (Zárate y Rubio, 2011; Miralles y Tulla, 2012).

Como consecuencia de este proceso de urbanización, el territorio se organiza en redes de relación espaciotemporales que lo articulan, lo integran y lo conectan con otros flujos (Nel.lo, 1996; Hall y Williams, 2002; Indovina, 2003; Vivas, 2004; Miralles y Tulla, 2012; Cuadrado et al., 2017). De este modo, la tradicional distinción entre ciudad y campo ya no se basa solo en la estructura económica, el nivel de renta, las formas de vida o el acceso a los servicios (Urry, 2002; López Colás y Módenes, 2005).

Dicho fenómeno provoca cambios en el paisaje de estos territorios, así como en su medio ambiente y en las actividades económicas, culturales y sociales que allí se desarrollan, ya que estos residentes temporales, además de disfrutar de la naturaleza y del mundo rural, así como del patrimonio cultural del destino, no desean perder tampoco sus ventajas urbanas, por lo que también demandan una serie de servicios y actividades similares a los que ya tienen habitualmente en la ciudad (Serrano, 2003; Ávila y Barrado, 2005; Vargas del Río, 2015).

Por otra parte, las viviendas secundarias, además de su importancia como uso personal, también poseen un valor económico por sí mismas, ya que pueden venderse y/o alquilarse. Además, por su durabilidad temporal, presentan un alto potencial de revalorización monetaria a largo plazo (Gili, 2003; Mazón y Aledo, 2005; Vinuesa, 2005).

Por ello, ante la competencia cada vez mayor entre destinos, la obsolescencia de algunos productos turísticos y las nuevas necesidades y demandas de los turistas, algunos territorios rurales con suficientes recursos patrimoniales aprovechan el creciente interés de la población urbana por el turismo cultural para comercializar su patrimonio, tanto tangible como intangible. Este proceso, que estaba inactivo o solo se limitaba al consumo autóctono, ha servido, además, para diversificar la oferta turística (Garay y Cànoves, 2009).

No obstante, este cambio de paradigma ha provocado, en ocasiones, una cierta deformación de la oferta, de modo que en algunos destinos incluso se ha podido llegar a realizar una cierta teatralización del producto para satis- 
facer al visitante. Algunas veces incluso ha derivado en su artificialización, con lo que se consolida la idea de que lo ficticio puede reemplazar a lo real. De este modo se pervierte la historia, pero se favorece la atracción turística (Antón, 2008).

Sea como sea, la creciente oferta de actividades de ocio y recreación en estos destinos no solo permite poner en valor turístico su patrimonio y atraer a más visitantes, sino que también ayuda a alargar su estancia, sea habitual o no. Un caso especial es el constituido por las personas urbanas jubiladas y prejubiladas que tienen una segunda residencia en la comarca, las cuales, al disponer también de los servicios más necesarios (sanitarios, comerciales, bancarios, recreativos, culturales, etc.) en muchos de estos territorios, prefieren alargar al máximo su permanencia y disfrutar de las ventajas del destino (naturaleza, tranquilidad, poca contaminación, múltiples actividades culturales y recreativas, etc.) (Gustafson, 2002; Phillips, 2010).

No se puede olvidar que las características del entorno inciden directamente en la calidad de vida de las personas. Por ello, cuando la población eminentemente urbana se traslada al mundo rural durante largos períodos de tiempo, la morfología metropolitana, los usos del suelo, la ubicación de las actividades y de los servicios, el diseño del espacio público, entre otros, son características de la ciudad que modelan la vida cotidiana de estos colectivos en el mundo rural (Scott, 2008; Phillips, 2010).

\section{Análisis del caso}

\subsection{Las viviendas secundarias y el turismo en la Baixa Cerdanya}

La Baixa Cerdanya es una comarca situada en medio de los Pirineos catalanes (figura 1), que, desde hace varias décadas y gracias a su situación E-W y a su climatología, así como a la facilidad de conectarse físicamente con la Región Metropolitana de Barcelona (RMB) por el túnel del Cadí, abierto en 1984, ha desarrollado significativamente el turismo, lo que ha aumentado considerablemente su oferta de productos y establecimientos turísticos (en cantidad y en plazas disponibles), pero muy especialmente las segundas residencias. Esta conversión de la comarca en destino turístico ha estado muy ligada, por una parte, a la nieve y a las estaciones de esquí y, por otra, al veraneo, al excursionismo y a la salud. De este modo, ha pasado de tener una economía tradicionalmente agraria y ganadera a otra basada en el turismo, la construcción y los servicios relacionados con estas actividades.

El inicio del turismo en la comarca se remonta a la segunda mitad del siglo XIX, cuando la burguesía bienestante barcelonesa, en busca de descanso, tranquilidad, un clima propicio, sol, aire puro y contacto con la naturaleza, empezó a construirse allí suntuosas villas para pasar el verano, principalmente junto al estanque de Puigcerdà. Este fenómeno también estuvo ligado a las inversiones de capital en bienes inmuebles.

Posteriormente, en 1908, se empezó a esquiar en La Molina, en el municipio de Alp, y en 1922 llegó el primer tren desde Barcelona hasta dicha 
Figura 1. Mapa de situación de la Baixa Cerdanya y sus municipios

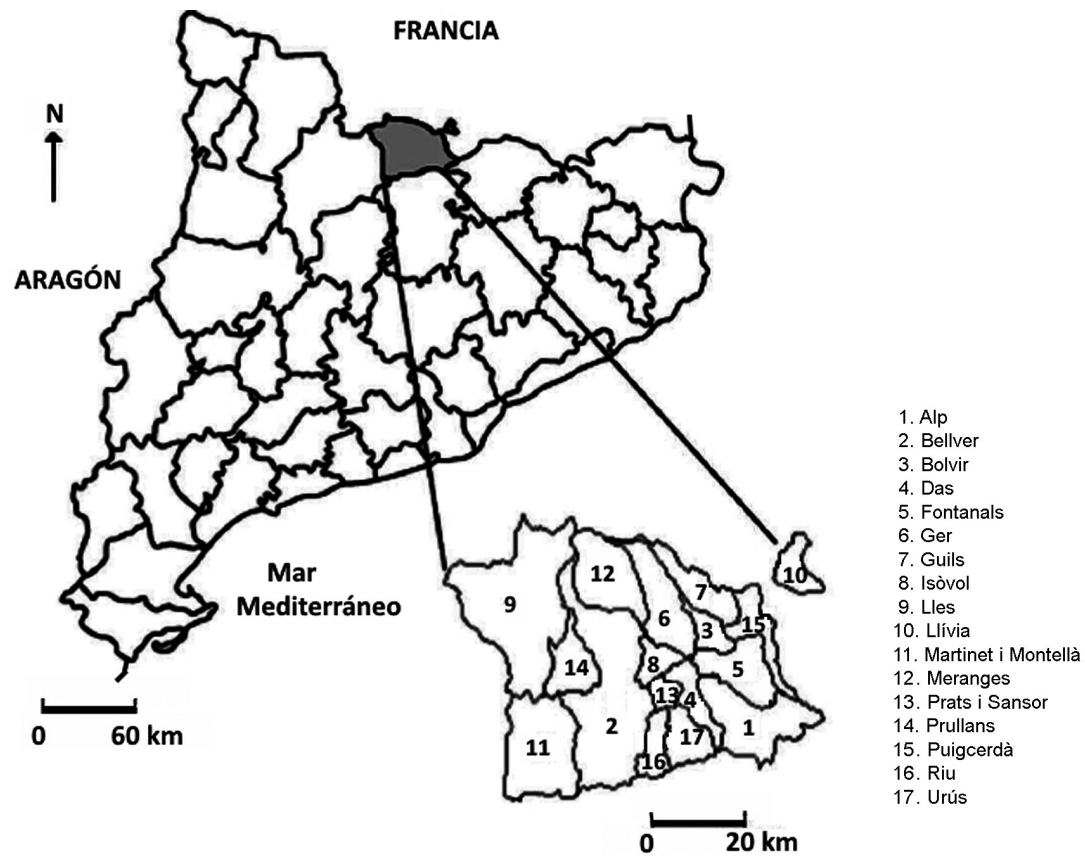

Fuente: elaboración propia.

estación de esquí y se prolongó hasta Puigcerdà. Más tarde, en 1929, se construyó el primer campo de golf de la comarca en el término municipal de Bolvir, alrededor del cual empezó a desarrollarse una urbanización de alto standing promocionada por dicha burguesía. Poco a poco, algunos residentes en Barcelona, pero con familia y/o propiedades rústicas en la comarca también empezaron a construirse residencias veraniegas en sus pueblos respectivos o acondicionaron sus antiguas casas de payés. Todo ello quedó truncado con la Guerra Civil y la postguerra, y no volvió a reiniciarse hasta finales de la década de 1960 .

Sin embargo, con la apertura del túnel del Cadí en 1984, que permitía la conexión con la Región Metropolitana de Barcelona en algo más de hora y media a través del eje del Llobregat (hay que tener en cuenta que antes, por la collada de Toses, se tardaba unas tres horas, y más de cuatro en tren), el fenómeno inmobiliario de las segundas residencias se incrementó notablemente, inicialmente con urbanizaciones en Prats y Das, que luego se fueron expandiendo por casi todos los municipios restantes.

El potencial de la comarca para acoger viviendas secundarias, además de disponer de atractivos recursos naturales y patrimoniales y de mejorar sustancialmente su accesibilidad, se pone de manifiesto si se tiene en cuenta que 
Tabla 1. Parque de viviendas de la comarca (1981-2011)

\begin{tabular}{lrrrr}
\hline & 1981 & 1991 & 2001 & \multicolumn{1}{c}{2011} \\
\hline Principales & 3.498 & 4.050 & 5.543 & 7.665 \\
Secundarias & 3.692 & 6.776 & 9.081 & 11.353 \\
Vacías/Otras & 1.749 & 1.251 & 1.231 & 2.168 \\
Comunitarias & - & 69 & 10 & 12 \\
Total & 8.939 & 12.146 & 15.865 & 21.198 \\
\hline
\end{tabular}

Fuente: IDESCAT (2017) a partir de los censos de población y vivienda del INE.

la RMB acoge a más de cinco millones de habitantes (de los que un $60 \%$ se encuentran en Barcelona y su primera corona metropolitana).

Así, la Baixa Cerdanya ha pasado de tener censadas 3.692 viviendas secundarias en 1981 a contar con 11.353 en 2011 (fecha del último censo oficial), lo que representa un crecimiento del 207,50\%; mientras que el número de residencias principales ha aumentado un $119,13 \%$, puesto que han pasado de 3.498 a 7.665 en el mismo período (tabla 1 ).

En 1981, las residencias secundarias representaban el 41,30\% del parque total de viviendas de la comarca, mientras que las principales constituían el 39,13\%. En 2011, el porcentaje de viviendas temporales subió hasta el $53,56 \%$, lo que significa un aumento de 12,26 puntos, mientras que las principales bajaron al $36,16 \%$, con una reducción de 2,97 puntos porcentuales.

Tal como puede apreciarse en la figura 2, el 16,74\% de las residencias secundarias existentes en el año 2011 se construyeron antes de 1971, mientras que el $20,50 \%$ lo hizo entre 1971 y 1980 ; el $16,06 \%$, entre 1981 y 1990 ; el $29,45 \%$, entre 1991 y 2001 , y el $17,26 \%$ restante, entre 2001 y 2010 . La influencia de la apertura del túnel del Cadí en 1984 se observa en que más del $56 \%$ de este tipo de viviendas fue construido después y que unas dos terceras partes del parque total fueron edificadas desde que se tuvo conocimiento de la realización de esta infraestructura viaria.

Si se analiza la distribución territorial en valores absolutos de las viviendas secundarias en estos cuatro años (1981, 1991, 2001 y 2011) en cada municipio de la comarca (figura 3), puede observarse que la mayor cantidad de estas se encuentra en los municipios de Alp (con las estaciones de esquí de La Molina y Masella como grandes focos de atracción turística), Puigcerdà (la capital de la comarca), Llívia (con su cercanía a las pistas de esquí francesas) y Bellver (capital de la subcomarca de la Batllia), todos con más de 1.000 residencias secundarias, mientras que los municipios con menos viviendas de este tipo son Meranges y Riu, donde no se llega a 100.

Comparando los mapas de estos cuatro años, se puede observar que el número de estas residencias ha aumentado en casi todos los municipios. Destaca el incremento de más de 1.000 viviendas secundarias entre 1981 y 2011 en los municipios de Alp, Puigcerdà y Llívia. Por el contrario, en Meranges su cifra casi no ha aumentado (solamente 16 entre estos dos años), mientras 
Figura 2. Viviendas secundarias en la comarca en 2011 y año de construcción

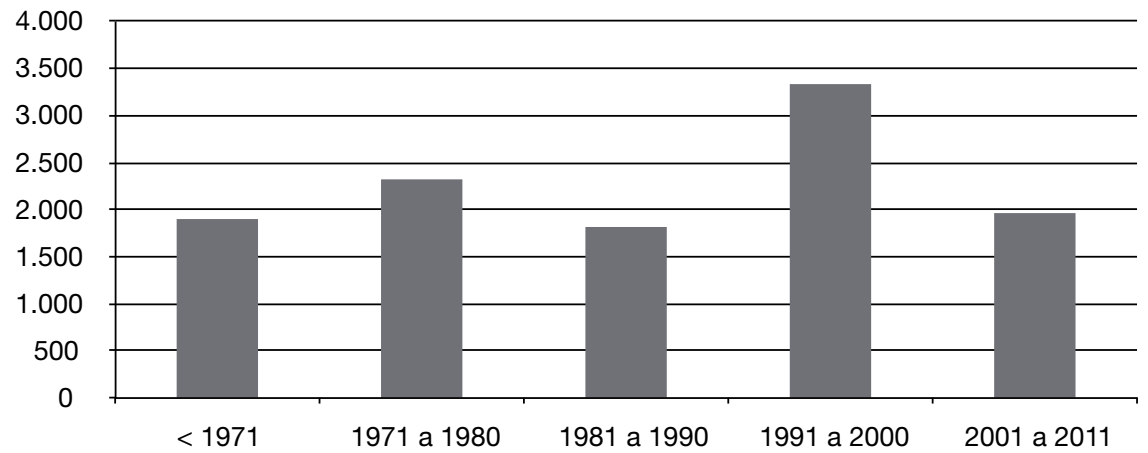

Fuente: IDESCAT (2017) a partir de los censos de población y vivienda del INE.

Figura 3. Distribución territorial de las viviendas secundarias

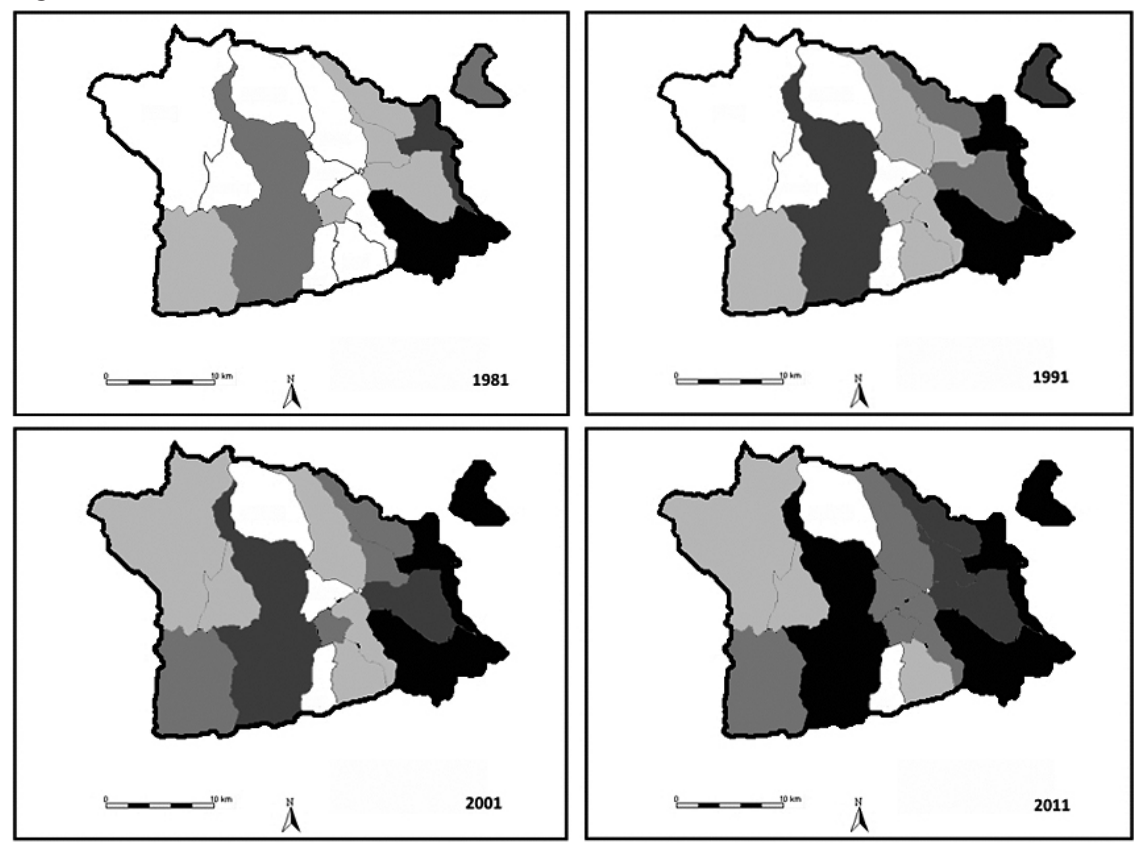

Fuente: elaboración propia con Miramon, a partir de IDESCAT (2017).

que en Montellà i Martinet, Prullans y Riu el crecimiento ha sido inferior a 100 viviendas.

En cuanto a la población censada y a la población estacional ETCA que había en la comarca entre los años 2002 y 2015, en la figura 4 se puede observar su evolución, así como el porcentaje de población ETCA que ha ido 
Figura 4. Evolución de la población residente y estacional (2002-2015)
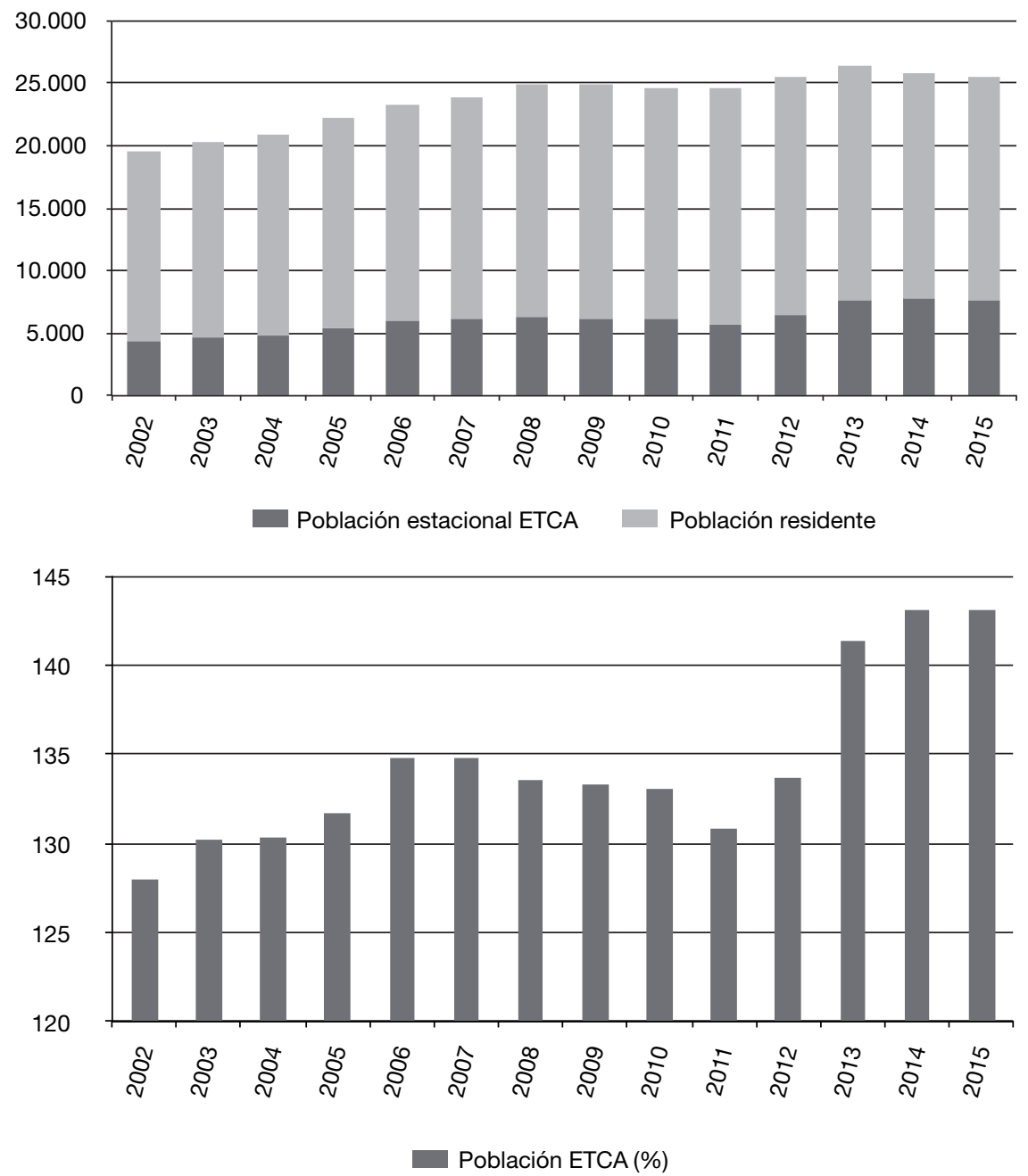

Fuente: elaboración propia a partir de IDESCAT (2017).

aumentando en estos años, que ha pasado del 128\% al 143,1\%, aunque entre 2008 y 2012 se nota el efecto negativo de la última crisis económica, al emigrar parte de una población residente que anteriormente era inmigrante.

Asimismo, si se analiza la evolución de la tasa de función turística residencial (TFR) para cada uno de los municipios de la comarca en estos cuatro años, siguiendo la fórmula propuesta en 1965 por Barbier (TFR del municipio = n. ${ }^{\circ}$ residencias secundarias / n. ${ }^{\circ}$ de viviendas principales), se obtiene el cuadro siguiente (tabla 2), donde puede apreciarse que dicha tasa supera la unidad (es 
Tabla 2. Evolución de la TFR de cada municipio (1981-2011)

\begin{tabular}{lllll}
\hline & 1981 & 1991 & 2001 & 2011 \\
\hline Alp & 4,52 & 5,48 & 4,08 & 10,04 \\
Bellver & 0,72 & 1,32 & 1,45 & 2,36 \\
Bolvir & 1,73 & 2,26 & 3,07 & 8,50 \\
Das & 2,34 & 2,66 & 3,21 & 6,70 \\
Fontanals & 1,71 & 3,52 & 5,27 & 9,61 \\
Ger & 1,06 & 1,73 & 1,09 & 3,68 \\
Guils & 1,58 & 3,68 & 1,96 & 5,92 \\
Isòvol & 0,43 & 0,69 & 0,09 & 5,65 \\
Lles & 0,72 & 1,03 & 1,41 & 1,88 \\
Llívia & 1,78 & 3,39 & 3,59 & 5,28 \\
Meranges & 1,04 & 1,76 & 1,63 & 1,60 \\
Montellà i Martinet & 1,00 & 0,61 & 1,24 & 1,32 \\
Prats i Sansor & 4,83 & 6,59 & 4,26 & 11,05 \\
Prullans & 1,21 & 1,42 & 1,49 & 2,21 \\
Puigcerdà & 0,38 & 0,85 & 0,60 & 0,86 \\
Riu & 0,88 & 1,60 & 1,31 & 3,72 \\
Urús & 2,47 & 4,29 & 3,35 & 5,57 \\
Cerdanya & 1,06 & 1,67 & 1,64 & 2,80 \\
\hline
\end{tabular}

Fuente: elaboración propia a partir de IDESCAT (2017).

decir, presenta más viviendas secundarias que principales) en la gran mayoría de los municipios.

Destacan Alp y Prats i Sansor, ambos con una TFR superior a 10 en el año 2011. La excepción a este fenómeno se encuentra fundamentalmente en la capital de la comarca, Puigcerdà, donde prevalecen las viviendas principales.

Por ello, la Baixa Cerdanya presentaba en su conjunto, en el año 2011, una tasa de funcionalidad turística residencial (TFR) de 2,80, que casi triplicaba el 1,06 que tenía en 1981, antes de la apertura del túnel del Cadí. Sin embargo, calculando la tasa de la función turística completa (TFT) de cada municipio, definida por Defert en 1970 según la fórmula: TFT = (plazas disponibles en el conjunto de establecimientos turísticos / población censada) x 100; entre los años 2000 y 2016 se obtiene el cuadro siguiente (tabla 3).

Tal como se puede observar en la tabla anterior, destaca la TFT del municipio de Prullans (con dos hoteles, un hostal y un campin, pero con una población censada relativamente baja), así como, en un porcentaje bastante inferior, los casos de Fontanals, Isòvol, Guils y Lles. Comparando los resultados de ambos años, son relevantes los incrementos de esta tasa en Prullans y Lles, mientras que en otros municipios se ha reducido (Bellver, Guils, Isòvol, Llívia, Meranges, Montellà i Martinet y Puigcerdà). Este último fenómeno ha ocurrido donde la población censada ha crecido más que la oferta de plazas en los establecimientos turísticos del municipio. 
Tabla 3. Evolución de la TFT de cada municipio (2000-2016)

\begin{tabular}{|c|c|c|c|c|c|}
\hline & TFT (2000) & TFT (2016) & & TFT (2000) & TFT (2016) \\
\hline Alp & $48,17 \%$ & $76,24 \%$ & Llívia & $16,51 \%$ & $7,57 \%$ \\
\hline Bellver & $68,59 \%$ & $64,71 \%$ & Meranges & $19,28 \%$ & $16,16 \%$ \\
\hline Bolvir & $7,89 \%$ & $27,20 \%$ & Montellà i Martinet & $25,20 \%$ & $17,18 \%$ \\
\hline Das & $14,81 \%$ & $8,84 \%$ & Prats i Sansor & $42,99 \%$ & $45,38 \%$ \\
\hline Fontanals & $95,81 \%$ & $105,83 \%$ & Prullans & $467,74 \%$ & $577,40 \%$ \\
\hline Ger & $8,35 \%$ & $12,84 \%$ & Puigcerdà & $23,28 \%$ & $18,16 \%$ \\
\hline Guils & $194,79 \%$ & $143,50 \%$ & Riu & $0,00 \%$ & $16,49 \%$ \\
\hline Isòvol & $147,96 \%$ & $141,67 \%$ & Urús & $3,17 \%$ & $6,08 \%$ \\
\hline Lles & $149,46 \%$ & $200,40 \%$ & Cerdanya & $45,74 \%$ & $44,71 \%$ \\
\hline
\end{tabular}

Fuente: elaboración propia a partir de IDESCAT (2017).

Así pues, las segundas residencias tienen una gran importancia en una comarca donde, en el año 2011, solamente en Puigcerdà y Martinet i Montellà había más viviendas principales que secundarias. Evidentemente, esta situación ha favorecido el desarrollo económico de dichos municipios en particular y de la comarca en general, ya que, además de las licencias de obras y de los ingresos anuales procedentes de la recaudación de los impuestos de bienes inmuebles (IBI), ha aumentado el trabajo en el sector de la construcción y de los accesorios, así como los servicios derivados de su mantenimiento (jardinería, lampistería, carpintería, trabajos del hogar, etc.) y otras actividades terciarias, como el comercio y la restauración.

No obstante, la estancia en muchas de estas residencias secundarias es de corta duración y muy estacional, ya que solamente se suelen ocupar unas pocas semanas al año, básicamente a lo largo del mes de agosto (especialmente en la primera quincena), Semana Santa y Fin de Año, amén de los puentes de los días festivos y algunos fines de semana (principalmente durante la temporada de esquí y en verano). Sin embargo, en estos últimos años algunas empiezan a permanecer abiertas durante más tiempo, gracias a los jubilados y a los prejubilados propietarios de este tipo de viviendas, que prefieren compaginar su estancia entre la ciudad y la segunda residencia.

\subsection{La oferta pública de actividades turisticas en la Baixa Cerdanya y su evolución}

Revisando las actividades recreativas, culturales y de naturaleza ofertadas desde los organismos públicos y las asociaciones locales sin ánimo de lucro y publicadas en las principales revistas de la prensa comarcal gratuita durante todos los meses de 2006 y 2016, se han obtenido los resultados presentados en la figura 5, donde puede observarse un fuerte incremento de estas actividades, que han pasado de 652 en el año 2006 a 1.384 en el 2016, es decir, se han duplicado en diez años.

En este aspecto destacan los municipios de Alp, Bellver, Llívia y Puigcerdà, con más de 50 actividades en 2016, mientras que en el resto no se ha llegado 
Figura 5. Actividades turísticas programadas mensualmente (2006 y 2016)

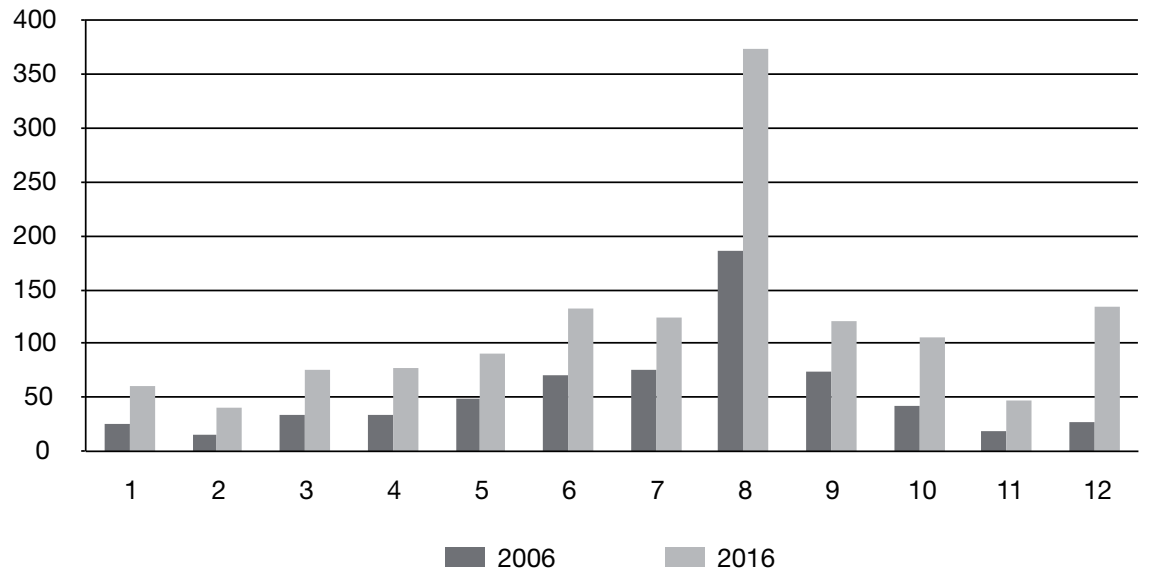

Fuente: elaboración propia.

a las 20. En este aumento global del 112,27\% destaca especialmente el mes de diciembre, donde se ha pasado de 27 a 135 actividades (el 400\%), mientras que los meses de julio y septiembre son los que han experimentado un aumento proporcionalmente menor, ligeramente superior al 60\%. En valores absolutos, el mes más activo ha sido agosto (con 183 actividades en 2006 y 374 en 2016).

Si nos fijamos individualmente en cada actividad ofertada (figura 6), veremos que destacan los talleres para jóvenes y adultos (que, de ser 80 en 2006, han pasado a 256 en 2016), los conciertos (de 111 a 182), los bailes (de 129 a 144) y los talleres y los juegos infantiles (de 62 a 114). Agrupando todas estas actividades por trimestres y comparando ambos años puede observarse que alrededor del $12 \%$ se realizan durante el primer trimestre, mientras que el 22\% tienen lugar en el segundo, el $49 \%$ en el tercero y el restante $17 \%$ en el cuarto. Así pues, el verano es la principal época del año donde se concentran estas actividades, una parte significativa de las cuales se realizan al aire libre.

De este modo puede apreciarse la existencia de una relación directa entre esta oferta de actividades lúdicas y recreativas, las vacaciones de verano y la gente de la ciudad que tiene una residencia temporal en la comarca.

Si se agrupan estas iniciativas en tres grandes grupos tipológicos (culturales, recreativas y de naturaleza), se obtiene la tabla 4 . En ella puede apreciarse que en ambos años predominan las actividades culturales y recreativas (las dos cercanas al 50\% del total ofertado), mientras que las que están orientadas a la naturaleza son muy minoritarias (alrededor del 5\%). Destaca el aumento de más de seis puntos porcentuales en el caso de las actividades recreativas, aunque este aumento se produce básicamente en detrimento de las culturales.

Por otra parte, si se analizan (tabla 5) las relaciones lineales existentes entre las actividades de este tipo realizadas anualmente en cada municipio con la población estacional ETCA en 2006, las residencias secundarias censadas en 
Figura 6. Actividades turísticas programadas anualmente (2006 y 2016)

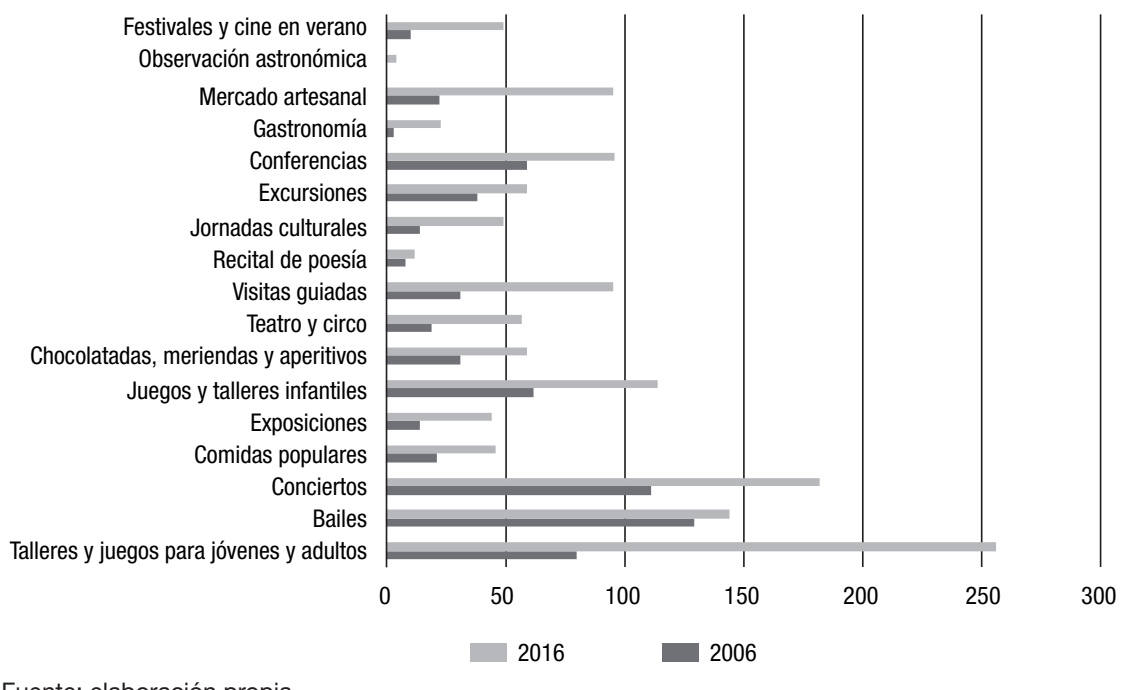

Fuente: elaboración propia.

2001 y las secundarias estimadas en 2006, puede observarse que en el año 2006 se produce una fuerte correlación $(\mathrm{R}=0,80)$ entre la población estacional ETCA y las actividades entonces realizadas, de modo que el $64 \%$ de los casos presentes se explican a partir de estas dos variables y el 36\%, no.

En cuanto a la correlación entre dichas actividades y las residencias secundarias, tanto las censadas en 2001 como las estimadas para 2006, los resultados son más moderados $(R=0,67)$, de forma que solamente el $45 \%$ de los casos presentados se explican a través de estas variables, mientras que en el $55 \%$ de ellos no se puede hacer.

Asimismo, tal como se aprecia en la tabla anterior, las relaciones lineales entre las actividades realizadas a lo largo del año 2016 en cada municipio con la población estacional ETCA en 2016 también son moderadas, aunque tienden hacia fuertes $(\mathrm{R}=0,78)$, por lo que el $60 \%$ de los casos se explica con estas variables, y el $40 \%$, no. A su vez, las relaciones lineales entre estas actividades y las residencias secundarias censadas en 2011 son fuertes $(R=0,85)$, de forma que el $72 \%$ de los casos se explica con estas variables. Finalmente, las relaciones

Tabla 4. Actividades realizadas anualmente por grupos tipológicos (2006 y 2016)

\begin{tabular}{lrr}
\hline & 2006 & 2016 \\
\hline Actividades culturales & $49,54 \%$ & $44,73 \%$ \\
Actividades recreativas & $44,63 \%$ & $51,01 \%$ \\
Actividades de naturaleza & $5,83 \%$ & $4,26 \%$ \\
\hline
\end{tabular}

Fuente: elaboración propia. 
Tabla 5. Resultados de los coeficientes de Pearson (R)

\begin{tabular}{lcc}
\hline & Actividades 2006 & Actividades 2016 \\
\hline Población estacional ETCA & 0,80 & \\
Residencias secundarias (est. 2006) & 0,67 & \\
Residencias secundarias (2001) & 0,67 & \\
\hline Población estacional ETCA & & 0,78 \\
Residencias secundarias (est. 2016) & & 0,83 \\
Residencias secundarias (2011) & 0,83 \\
Plazas hoteleras (2015) & & 0,67 \\
Plazas de campin (2015) & & 0,32 \\
Plazas de turismo rural (2015) & 0,11 \\
Plazas totales en los establecimientos turísticos (2015) & & 0,62 \\
\hline
\end{tabular}

Fuente: elaboración propia.

lineales entre estas actividades y las residencias secundarias estimadas para 2016 también son fuertes $(R=0,83)$, de modo que estas variables pueden explicar el $69 \%$ de los casos presentes.

En la misma tabla puede verse que las relaciones lineales entre estas actividades en 2016 y las plazas hoteleras en cada municipio de la comarca son moderadas tendiendo a fuertes $(R=0,67)$, de modo que estas dos variables solamente pueden explicar el $45 \%$ de los casos. A su vez, las relaciones entre dichas actividades y las plazas de campin son débiles $(R=0,32)$, puesto que solo se explica el $10 \%$ de los casos, mientras que con las plazas de turismo rural son todavía más débiles, casi inexistentes $(\mathrm{R}=0,11)$. Asimismo, si se analizan las relaciones lineales de estas actividades con el conjunto de todas las plazas disponibles en los establecimientos turísticos de la comarca, la relación es moderada $(R=0,62)$, de modo que estas dos variables solamente justifican el $38 \%$ de los casos presentados.

Por otra parte, las correlaciones lineales entre estas actividades en 2016 y las tasas de la función turística completa (TFT) y de la función turística residencial (TFR) son decrecientes y muy débiles, ya que ambas presentan un coeficiente de Pearson (R) negativo y con valores absolutos inferiores a 0,20.

En cuanto a los resultados de la encuesta realizada a los residentes y a los turistas que acuden a estos eventos, en la tabla 6 puede observarse que el grado de satisfacción de los encuestados con esta actividad es bastante alto $(3,79$ sobre 5), y es mejor valorado por los encuestados que tienen en la comarca una residencia secundaria $(3,90)$. Por su parte, el grado de participación directa de los encuestados cuando acuden a estas actividades también es similar (3,78 sobre 5). En este aspecto destacan los habitantes permanentes $(4,11)$ y los que tienen allí una segunda residencia $(3,85)$. El mismo fenómeno se produce con la posibilidad de repetición de la actividad en una ocasión futura $(3,80$ sobre 5), especialmente por parte de los residentes con vivienda principal en la comarca $(3,94)$ y los que poseen allí una segunda residencia $(3,89)$. Finalmente, la posibilidad de aconsejar esta actividad a otras personas también es alta 
Tabla 6. Resultados globales de la encuesta

\begin{tabular}{lcccc}
\hline & $\begin{array}{c}\text { Vivienda } \\
\text { habitual }\end{array}$ & $\begin{array}{c}\text { Vivienda } \\
\text { secundaria }\end{array}$ & $\begin{array}{c}\text { En establecimientos } \\
\text { turísticos }\end{array}$ & Total \\
\hline Satisfacción con la actividad & 3,63 & 3,90 & 3,60 & 3,79 \\
Grado de participación directa & 4,11 & 3,85 & 3,04 & 3,78 \\
Posibilidad de repetición & 3,94 & 3,89 & 3,24 & 3,80 \\
Posibilidad de prescripción & 4,11 & 3,95 & 3,48 & 3,91 \\
\hline
\end{tabular}

Fuente: elaboración propia.

(3,91 sobre 5$)$, lo que está en consonancia con la satisfacción obtenida con la misma, destacan los habitantes habituales $(4,11)$ y los que tienen una vivienda secundaria en la comarca $(3,95)$.

Seguidamente, se presentan los resultados porcentuales de la encuesta por cada una de las tres tipologías de residencia en la comarca (vivienda principal, vivienda secundaria y estancia en un establecimiento turístico), así como el total (tabla 7).

En la tabla anterior puede apreciarse que más del 80\% de los encuestados con residencia habitual en la comarca otorgan una valoración alta o muy alta a su participación directa en las actividades programadas, mientras que alrededor del 70\% valoran muy positivamente dichas actividades y manifiestan la intención de repetir la experiencia y recomendarla. Por su parte, alrededor del $80 \%$ de los encuestados con segunda vivienda en la comarca están satisfechos con estas actividades, participan en ellas y esperan repetirlas, mientras que cerca

Tabla 7. Resultados porcentuales de los encuestados por tipologías de residencia

\begin{tabular}{|c|c|c|c|c|c|c|}
\hline & & Muy bajo & Bajo & Medio & Alto & Muy alto \\
\hline \multirow[t]{4}{*}{ Vivienda habitual } & Satisfacción con la actividad & $5,71 \%$ & $11,43 \%$ & $22,86 \%$ & $34,29 \%$ & $25,71 \%$ \\
\hline & Grado de participación directa & $0,00 \%$ & $2,86 \%$ & $14,29 \%$ & $51,43 \%$ & $31,43 \%$ \\
\hline & Posibilidad de repetición & $2,86 \%$ & $11,43 \%$ & $17,14 \%$ & $25,71 \%$ & $42,86 \%$ \\
\hline & Posibilidad de prescripción & $2,86 \%$ & $2,86 \%$ & $17,14 \%$ & $34,29 \%$ & $42,86 \%$ \\
\hline \multirow[t]{4}{*}{ Vivienda secundaria } & Satisfacción con la actividad & $3,19 \%$ & $4,26 \%$ & $11,70 \%$ & $60,64 \%$ & $20,21 \%$ \\
\hline & Grado de participación directa & $2,13 \%$ & $5,32 \%$ & $15,96 \%$ & $58,51 \%$ & $18,09 \%$ \\
\hline & Posibilidad de repetición & $2,13 \%$ & $5,32 \%$ & $10,64 \%$ & $64,89 \%$ & $17,02 \%$ \\
\hline & Posibilidad de prescripción & $3,19 \%$ & $6,38 \%$ & $15,96 \%$ & $41,49 \%$ & $32,98 \%$ \\
\hline \multirow{4}{*}{$\begin{array}{l}\text { En establecimientos } \\
\text { turísticos }\end{array}$} & Satisfacción con la actividad & $4,00 \%$ & $12,00 \%$ & $24,00 \%$ & $40,00 \%$ & $20,00 \%$ \\
\hline & Grado de participación directa & $8,00 \%$ & $24,00 \%$ & $32,00 \%$ & $28,00 \%$ & $8,00 \%$ \\
\hline & Posibilidad de repetición & $4,00 \%$ & $24,00 \%$ & $24,00 \%$ & $40,00 \%$ & $8,00 \%$ \\
\hline & Posibilidad de prescripción & $4,00 \%$ & $12,00 \%$ & $28,00 \%$ & $44,00 \%$ & $12,00 \%$ \\
\hline \multirow[t]{4}{*}{ Total } & Satisfacción con la actividad & $3,90 \%$ & $7,14 \%$ & $16,23 \%$ & $51,30 \%$ & $21,43 \%$ \\
\hline & Grado de participación directa & $2,60 \%$ & $7,79 \%$ & $18,18 \%$ & $51,95 \%$ & $19,48 \%$ \\
\hline & Posibilidad de repetición & $2,60 \%$ & $9,74 \%$ & $14,29 \%$ & $51,95 \%$ & $21,43 \%$ \\
\hline & Posibilidad de prescripción & $3,25 \%$ & $6,49 \%$ & $18,18 \%$ & $40,26 \%$ & $31,82 \%$ \\
\hline
\end{tabular}

Fuente: elaboración propia. 
de un 75\% tiene la intención de prescribirlas. Por el contrario, los encuestados que residen en los establecimientos turísticos, aunque también valoran mayoritariamente estas actividades, participan menos en ellas y también es menor su intención de repetirlas, aunque sí están dispuestos a prescribirlas.

Los encuestados con residencias principales en la comarca son los que realizan más participación directa en estas actividades (con una valoración media de 4,11), seguidos por los que tienen una residencia secundaria allí $(3,85)$ y los que pernoctan en alguno de los establecimientos turísticos $(2,17)$.

Sin embargo, la mayor satisfacción con la actividad realizada la presentan los que tienen una vivienda secundaria $(3,90)$, seguidos por los que viven allí habitualmente $(3,63) \mathrm{y}$, a mayor distancia, los que se encuentran en los establecimientos turísticos $(2,57)$.

En cuanto a la intención de repetir la actividad en el futuro, los tres grupos de encuestados dan valoraciones similares (3,93 los residentes habituales, 3,89 los de las residencias secundarias y 3,80 el resto). Asimismo, la posibilidad de recomendar la experiencia está más valorada por los que viven habitualmente en la comarca $(4,11)$, algo menos por los que tienen allí una segunda residencia $(3,63)$ y más débilmente por los restantes $(2,49)$.

En definitiva, la mayoría de los encuestados muestran una alta satisfacción con la programación de estas actividades, participen o no directamente en las mismas, aunque el colectivo más satisfecho con ellas es el formado por los que tienen una residencia secundaria en la comarca, mientras que los que viven habitualmente allí valoran más la participación directa en las mismas, esperan repetirlas y las recomiendan.

\section{Conclusiones}

Tal como se ha podido comprobar en este trabajo, la Baixa Cerdanya, que en estas últimas décadas se ha consolidado como un importante destino turístico, tanto de verano como de invierno, también se ha convertido en uno de los lugares favoritos, al menos en los territorios de interior, para las viviendas secundarias, especialmente desde la apertura del túnel del Cadí en 1984, de forma que en muchos municipios se han convertido en mayoritarias. Se trata de un parque reciente (más del 56\% se ha edificado después de este evento) y en continua expansión.

De este modo se ha generado una importante industria alrededor del turismo y de la construcción, así como de las actividades auxiliares y los servicios, en detrimento de las tradicionales actividades de agricultura y ganadería. Estas características están muy relacionadas con las peculiaridades del sector turístico español, que se caracteriza por la propensión de la población urbana a disfrutar de segundas residencias. Así, por ejemplo, el desarrollo de todas las estaciones de esquí catalanas está ligado a los planes urbanísticos y a la demanda de residencias secundarias.

Sin embargo, este fenómeno ha provocado un aumento de la población estacional y una ocupación muy limitada de las viviendas secundarias, ya que 
solo se habitan en determinados momentos del año, aunque últimamente el colectivo de las personas jubiladas y prejubiladas que tienen allí una residencia de este tipo parece que alarga su permanencia en el destino.

De este modo, la gran mayoría de municipios de la Baixa Cerdanya presenta una alta tasa de función residencial (es decir, más viviendas secundarias que principales), exceptuando el caso de la capital, Puigcerdà. En este aspecto destacan Alp y Prats i Sansor, con una tasa superior a 10. Sin embargo, la tasa de función turística (plazas disponibles en los establecimientos turísticos respecto a la población censada en cada municipio) ha permanecido bastante estabilizada en estas últimas décadas, con excepción de Alp y Bolvir.

Este aumento de las segundas residencias ha ido acompañado por un incremento de las actividades orientadas al ocio y a la recreación, especialmente cultural, que organizan, subvencionan y/o promocionan los organismos públicos de la comarca y las asociaciones locales sin ánimo de lucro (destaca en dicho aspecto el papel de los ayuntamientos). De esta forma, este tipo de actividades se ha doblado en estos últimos diez años, aunque casi la mitad se han realizado a lo largo del tercer trimestre, especialmente durante el mes de agosto, por lo que se han orientado fundamentalmente a dar satisfacción a las demandas de una población estacional que, en gran parte, posee una vivienda secundaria en la comarca. Entre estas actividades destacan numéricamente los talleres y los juegos infantiles y para adultos, los bailes y los conciertos.

El importante aumento de este tipo de actividades para que la población estacional se encuentre satisfecha en el territorio, alargue su estancia allí durante el máximo tiempo posible, disminuya su temporalidad, repita la experiencia en años venideros y la recomiende a otra gente está cumpliendo el objetivo de satisfacer principalmente, aunque no exclusivamente, las motivaciones de una población urbana que ha absorbido socialmente al mundo rural, sus costumbres y actividades. No obstante, este fenómeno ha desembocado, en ocasiones, en una cierta tematización de las actividades culturales ofertadas, lo que podría conducir a su teatralización, aunque, al menos de momento, esta circunstancia no se está produciendo todavía en el caso de la comarca aquí analizada.

En este artículo se ha podido comprobar que existe un grado de correlación bastante alto de estas actividades con las viviendas secundarias y con la población estacional, mientras que la correlación que presentan con las plazas disponibles en los establecimientos turísticos es muy débil, especialmente en los cámpines y el alojamiento rural. Asimismo, la satisfacción con estas actividades es bastante alta, especialmente entre la población con segunda residencia en la comarca, mientras que la población permanente es la que más valora la participación directa en las mismas, tiene mayor intención de repetirlas y más las recomienda.

En cuanto a las dos hipótesis planteadas al inicio de este artículo, se ha podido comprobar que, efectivamente, este tipo de actividades ha aumentado en estos últimos años en la comarca, ha provocado una satisfacción a sus espectadores y participantes y no ha generado, al menos de momento, conflictos en el uso del espacio público. Además, también se ha confirmado la existencia de 
una fuerte relación entre las residencias secundarias y dichas actividades, que va aumentando a medida que crecen ambas.

En definitiva, puede decirse que la mayor facilidad de movilización de la población urbana en las últimas décadas ha provocado que muchos destinos de interior, aprovechando sus recursos naturales y/o culturales, hayan modificado sus actividades tradicionales, siendo el turismo, la construcción de segundas residencias y los servicios el nuevo motor económico de estos territorios.

En algunos de estos destinos, como en el caso de la comarca aquí analizada, ha aumentado de manera muy significativa la cantidad de este tipo de viviendas. No obstante, este crecimiento ha venido parejo con estancias cortas y estacionales, aunque en estos últimos años la duración de dichas permanencias está aumentando, especialmente entre los colectivos de gente mayor y con un cierto poder adquisitivo.

En esta situación, desde los organismos y las asociaciones locales se están apoyando y/o programando una serie de actividades deportivas, culturales, lúdicas y recreativas que permiten una mayor involucración de los residentes temporales, así como la profundización de su conocimiento sobre el patrimonio del territorio. Dichas actividades también sirven para dar satisfacción a demandas de la propia población local y para interrelacionar los residentes con los foráneos, especialmente en los municipios pequeños.

De este modo, se están construyendo unos espacios donde se realizan actividades de ocio, entretenimiento, educación y cultura, muchas veces organizados en torno a determinadas líneas argumentales. No obstante, esta ocupación del espacio público y esta urbanización social del territorio pueden provocar la aparición de intereses contrapuestos y, a menudo, contradictorios entre la población autóctona y la temporal, lo que, en caso de ocurrir, provocaría que la convivencia entre ambos colectivos pudiera llegar a ser problemática y, eventualmente, conflictiva.

El modelo de desarrollo del turismo en los territorios rurales, especialmente de montaña, basado en la expansión de las segundas residencias, tiene algunas ventajas a corto plazo, esencialmente económicas, pero también plantea muchas incógnitas a medio y a largo plazo, especialmente en referencia a los temas medioambientales.

En consecuencia, sería oportuno disponer de una regulación exhaustiva de este modelo de crecimiento que, en abundantes ocasiones, ha provocado un deterioro del paisaje, que es uno de los principales productos que se utilizan como reclamo turístico en estos destinos. Contrariamente, los resultados observados hasta ahora son, en muchos casos, paisajes fracturados y desordenados.

Por ello, para beneficiar a la mayoría de la población, es necesaria una vertebración racional del destino turístico, defendiendo el derecho de todos a disfrutarlo, programando actividades de interés conjunto, persiguiendo su eficiencia funcional y su calidad medioambiental.

Para el futuro, creemos que sería interesante continuar la línea de investigación aquí iniciada comparando estos resultados con los de otras comarcas 
con distinto grado de desarrollo turístico, y así, desde los organismos oficiales, poder tomar las medidas preventivas urbanísticas y recreativas oportunas que eviten que se materialice este peligro y se pueda canalizar el esfuerzo común hacia la sostenibilidad del territorio.

Finalmente, hay que dejar constancia de que, con el objetivo de alcanzar mayor competitividad o simplemente mantenerse, muchos destinos de este tipo están diversificando su oferta de productos y servicios, especialmente cuando dependen mayoritariamente de fenómenos naturales como la nieve, el sol o el clima. Ello provoca el diseño y la puesta en marcha de nuevas actividades de montaña, principalmente desde el ámbito privado. En este artículo no se han analizado dichas actividades, que, en ocasiones, pueden alcanzar una cierta relevancia.

\section{Referencias bibliográficas}

Antón, S. (2008). The Global Theme Park Industry. Oxford (UK): Cabi.

ANTÓN, S. e IBARgUREN, B. (1993). «Espacios periurbanos de ocio, espacio y uso metropolitano del espacio en Barcelona». Mediterranée, 77 (1), 61-64.

Ávila, R. y BARRADO, D.A. (2005). «Nuevas tendencias en el desarrollo de destinos turísticos: Marcos conceptuales y operativos para su planificación y gestión». Cuadernos de Turismo, 15, 27-43.

BARBIER, B. (1965). «Méthodes d'étude des residences secondaires: L'exemple des Basses Alpes». Mediterranée, 2, 89-111.

CostA, L. y PUnTí, M. (2013). «Premsa gratüita, un model de comunicació local». Comunicació: Revista de Recerca i d'Anàlisi, 30 (1), 79-99.

CuAdrado, S.; DuRÀ, A. y SAlVATI, L. (2017). «Not only tourism: Unravelling suburbanization, second-home expansion and "rural" sprewl in Catalonia, Spain». Urban Geography, 38 (1), 66-89.

DEFERT, P. (1960). Le tourisme dans l'expansión regionale: Principes et methods. Vol. I. Berna: Editions Gurten.

DeLgado, C. (2008). «Vivienda secundaria y turismo residencial como agentes de urbanización y segregación territorial en Cantabria». Scripta Nova: Revista Electrónica de Geografia y Ciencias Sociales, XII (261). Recuperado de <http://www. ub.es/geocrit/sn/sn-269.htm>.

FRAGUELL, R. (1994). Turisme residencial i territori: La segona residència a la regió de Girona. Girona: L'Eix Editorial.

GARAY, L.A. y CÀnOVES, G. (2009). «El desarrollo turístico en Cataluña en los dos últimos siglos: Una perspectiva transversal». Documents d'Anàlisi Geogràfica, 53, $29-46$.

García GonzÁlez, J.A.; Cebrián, F. y Panadero, M. (2008). «El turismo de segunda residencia en el interior peninsular». Scripta Nova: Revista Electrónica de Geografía y Ciencias Sociales, XII (270). Recuperado de <http://www.ub.es/geocrit/sn/sn-270/ sn-270-94.htm>.

GILI, M. (2003). «Las viviendas de segunda residencia: ¿¿Ocio o negocio?». Scripta Nova: Revista Electrónica de Geografia y Ciencias Sociales. Barcelona: Universidad de Barcelona, 7 (146). Recuperado de <http://www.ub.es/geocrit/sn/sn-146(052).htm>.

GustafsOn, P. (2002). «Tourism and seasonal retirement migration». Annals of Tourism Research, 29 (4), 899-918. 
Hall, C.M. y Williams, A. (2002). Tourism and migration: New relationships between production and consumption. Dordrecht: Kluwer Academic Publishers.

HARVEY, D. (1994). "Flexible accumulation throught urbanization: Reflections on "post-modernism" in the american city». En: Amin, A. (coord.). Post-fordism. Oxford y Cambridge: Blackwell.

IDESCAT (Institut D'Estadística de Catalunya) (2017). Bases de datos de municipios y comarcas. Barcelona: IDESCAT. Recuperado de <http://www.idescat.cat/ territori/?geo $=$ mun $>$.

InDOVINA, F. (2003). "La "metropolizzazione del territorio": Nuove gerarchie territoriali». Economia e Società Regionale, 21 (3/4), 46-85.

López ColÁs, J. y Módenes, J.A. (2005). «Segona residència i multiresidència a Catalunya: Una aproximació sociodemogràfica». Documents d'Anàlisi Geogràfica, 46, 41-62.

LUNDGREN, J.O.J. (1974). «On acces to recreational lands in dynamic metropolitan hinterlands». Tourism Revue, 29 (4), 124-132.

Mazón, T. y Aledo, A. (2005). «El dilema del turismo residencial: ¿'Turismo o desarrollo inmobiliario?». En: MAZÓn, T. y Aledo, A. (eds.). Turismo residencial y cambio social: Nuevas perspectivas teóricas y empiricas. Alicante: CAM, FRAX, Universidad de Alicante, 13-30.

Miralles, C. y Tulla, A.F. (2012). «La Región Metropolitana de Barcelona: Dinámicas territoriales recientes». Boletín de la Asociación de Geógrafos Españoles, 58, 299-318.

Módenes, J.A. y López ColÁs, J. (2005). «Expansión territorial de la residencia secundaria y ciudad compacta en España: ¿Elementos de un mismo sistema?». Papers, 274.

Müller, D.K.; Hall, C.M. y KeEN, D. (2004). «Second home tourism impact, planning and management». En: Hall, C.M. y Müller, D.K. (coord.). Tourism, mobility and second homes: Between elite landscape and common ground. Clevedon, Buffalo, Toronto: Channel View Publications.

NEL·LO, O. (1996). «La ciudad dispersa: Suburbanización y nuevas periferias». Los confines de la ciudad sin confines: Estructura urbana y limites administrativos en la ciudad difusa, seminario realizado en Barcelona entre los meses de febrero y abril de 1996. Recuperado de <http://www.cccb.org/ca/>.

Pallarès, R. y Riera, P. (1991). «La residència secundaria». Papers, 8.

Phillips, M. (2010). "Counterurbanisation and rural gentrification: An exploration of the terms». Population, Space and Place, 16, 539-588.

Prat, J.M. y CÃNOVES, G. (2012). «El patrimonio industrial como dinamizador del territorio: El caso del ecomuseo La Farinera, en Castelló d'Empúries (Cataluña)». Documents d'Anàlisi Geogràfica, 58 (1), 79-100. <https://doi.org/10.5565/rev/dag.192>

PRAT, J.M. y DíAZ, I. (2014). «La repetición de visitas en el turismo industrial: Aplicación de un modelo de ecuaciones estructurales en el Bages y el Berguedà». Documents d'Anàlisi Geogràfica, 60 (2), 349-368. $<$ https://doi.org/10.5565/rev/dag.88>

SсотT, M. (2008). «Managing rural change and competing rationalities: Insights from conflicting rural storylines and local policy making in Ireland». Planning Theory and Practice, 9, 9-32.

SERrANO, J.M. a (2003). «Las segundas residencias en la sociedad del "bienestar": El caso de un país turístico: España». Cuadernos de Turismo, 12, 53-75. 
SojA, E.W. (1989). Postmodern Geographies: The Reassertion of Space in Critical Social Theory. Nueva York: Verso.

SouZA, E. de (2012). "Relación ciudad-campo y turismo rural: Ensayos teórico-metodológicos». Estudios y Perspectivas en Turismo, 21, 1-19.

Torres, E. (2003). «El turismo residenciado y sus efectos en los destinos turísticos». Estudios Turísticos, 155-156, 45-70.

URRY, J. (2002). The tourist gaze. Londres: Sage.

VARGAS DEL Río, D. (2015). «Turismo de segundas residencias y turismo de naturaleza en el espacio rural mexicano». Estudios Sociales, XXIII (46), 290-312.

VinUESA, J. (2005). "Dinámica demográfica, mercado de la vivienda y territorio». Papeles de Economía Española, 104, 253-270.

VIVAS, J. (2004). «La Cerdanya, una ciutat al tombant del mil.lenni?: Metamorfosi de l'espai, la identitat i el paisatge cerdà». Bellaterra (Barcelona): Universitat Autònoma de Barcelona. Tesis doctoral.

Zárate, M.A. y Rubio, M.T. (2011). Paisaje, sociedad y cultura en Geografía Humana. Madrid: Editorial Universitaria Ramón Areces.

ZukIN, S. (1995). The Cultures of Cities. Oxford: Blackwell. 